\title{
Effect of Different Aging Time Solution and Annealing Temperature on the Structural and Magnetic Properties of YIG Thin Films Prepared by a Sol-Gel Method
}

\author{
N. Zahirah M.Z'1, N.B. Ibrahim ${ }^{2}$ \\ School of Applied Physics, Faculty of Science and Technology, Universiti Kebangsaan Malaysia, 43600 Bangi \\ Selangor \\ Email: ${ }^{1}$ zahirah24@gmail.com, ${ }^{2}$ baayah@ukm.edu.my
}

\begin{abstract}
Sol-gel yttrium iron garnet films were prepared at different solution aging time and annealing temperature. Microstructure analysis using an X-ray diffractometer showed that aging time reduced the annealing temperature to crystallize the YIG thin films. The crystallite size increased with the aging and annealing time. The average particle size measured using a field emission scanning microscope is in the range of 19.62 to $49.12 \mathrm{~nm}$. The thickness of the films were between 49.13 to $72.63 \mathrm{~nm}$. The results from a vibrating sample magnetometer used to measure the magnetic properties showed that the magnetization saturation of the films increased with the increment of solution aging time.
\end{abstract}

Keywords: Thin film, Yttrium Iron Garnet (YIG), sol-gel, aging.

\section{Introduction}

Yttrium Iron Garnet (YIG) is a well-known ferrite material that is widely used for microwave devices, magneto-optical devices and optical communication [1]. There are many different techniques or methods which can be emploved to prepare YIG such as a sol-gel method [2-4], a solid state reaction technique [5], Low-Pressure Chemical Vapor Deposition (LPCVD) technique [6] and chemical co precipitation [7]. Among these techniques/methods, a sol-gel method is the most famous method. Apart from being a cheap and simple method, the composition of resultant film of sol-gel method can be also controlled. Among the parameters that can influence resultant of the sol-gel method are chelating agents [2], solution concentration [2], $\mathrm{pH}$ of the solution [3], annealing temperature and aging time of the solution. Ftema et al, [3] have reported on the influence of $\mathrm{pH}$ value on the structure and magnetic properties of YIG thin films. They found that higher $\mathrm{pH}$ value produces film with bigger particle size and higher saturation magnetization.

N.B Ibrahim et al. [8] have reported that the longest aging solution produces Zinc Oxide (ZnO) film with the best crystalline and optical properties. The film is also thick and has larger particle size. Ebru [9] has also reported that the aging solution of lead zirconate titanate, $\mathrm{Pb}\left(\mathrm{Zr}_{\mathrm{x}} \mathrm{Ti}_{1-\mathrm{x}}\right) \mathrm{O}_{3}(\mathrm{PZT})$ can change the preferred orientation and decrease the electrical properties of the films. S.M Rozati [10] reported the aged solution affects the structure, morphology and optical properties of fluorine-doped $\mathrm{ZnO}$ film. The intensity of crystallinity peak and optical transmittance increases with the increasing aging time. For the particle size, it decreases with the increasing aging day solution. However, there is no report so far about the effect of solution aging on YIG thin film prepared by a sol-gel method.

In this study, the effect of annealing temperature and aging time on the structural and magnetic properties of YIG thin films by a sol-gel method is reported. The YIG solution was aged for 0 (fresh), 2, 7 and 11 days with different annealing temperature, $700^{\circ} \mathrm{C}, 800^{\circ} \mathrm{C}$ and $900^{\circ} \mathrm{C}$.

\section{Experimental Method}

Yttrium Iron Garnet (YIG) thin films on quartz substrate were prepared using a sol-gel method followed by a spin coating technique. The compounds of yttrium nitrate hexahydrate, and iron nitrate 
nanohydrate were accurately weighted in the molecular mole fraction and then dissolved in ethylene glycol and stirred for 24 hours. The solutions were mixed together, then refluxed for 6 hours at $80^{\circ} \mathrm{C}$. Glacial acetic acid as a chelating agent was added after 3 hours to obtain solution with $\mathrm{pH}=3$. This $\mathrm{pH}$ value is important because during the gelation process, the formation of the polymeric three dimensional structure of the gel is highly influenced by the $\mathrm{pH}$ value of the solution [6]. After the reflux process, the solution was stirred for 48 hours to homogenize the solution. The YIG solution was aged in a temperature of $27^{\circ} \mathrm{C}$ (Malaysia's room temperature) for 0 (fresh), 2, 7 and 11 days. Then $0.25 \mathrm{ml}$ of the solution was dropped onto a cleaned quartz substrate. The substrate was spin coated at $3000 \mathrm{rpm}$ for 30 seconds, using a spin coater. Then the samples were annealed at 700,800 , and $900^{\circ} \mathrm{C}$ for 2 hours in oxygen gas.

The phase and crystal structure of the samples were analyzed by an X-ray diffractometer (XRD, D8 Advance Bruker) with $\mathrm{Cu} \mathrm{K} \alpha$ radiation $(\lambda=1.540598 \AA)$. A field emission scanning microscope (FESEM, Merlin Compact) was used to examine the surface morphology of the film. The samples were coated with platinum to prevent the electrostatic charges during the characterization to obtain the best images. A vibrating sample magnetometer (VSM, Lakeshore, Model 7300 series) was used to investigate the magnetic properties at $27^{\circ} \mathrm{C}$. The magnetic hysteresis loops were corrected for paramagnetic signal from the substrate.

\section{$3 \quad$ Results and Discussion}

\subsection{Structural Characteristics of Yttrium Iron Garnet Thin Films}

All films except film aged for 0 days start to crystallize at $700^{\circ} \mathrm{C}$ (see Fig. 1). Film aged for 0 days starts to crystallize at $800^{\circ} \mathrm{C}$. YIG thin film annealed at $900^{\circ} \mathrm{C}$ with all solution aging days having a good structural characteristic. These results show that aging time can reduce the annealing temperature to crystallize YIG film prepared by a sol-gel method, using ethylene glycol as a solvent and glacial acetic acid as a chelating agent. The peaks of garnet are indexed with the cubic crystal structure JCPDS card no 00-043-0507. Fig.1 shows that YIG thin film deposited with 7 days aging solution has a good garnet structure compared to the other films.
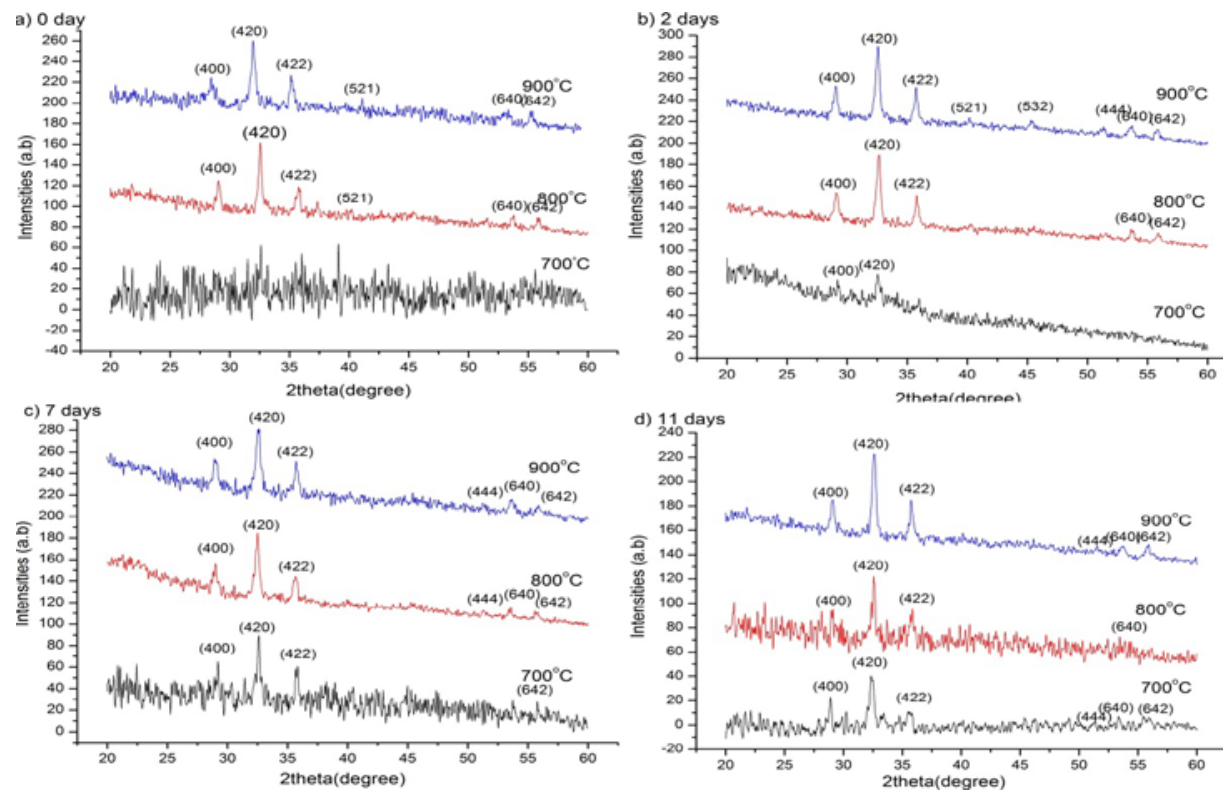

Figure 1. X-ray diffraction pattern of YIG thin films deposited with different annealing temperature with a different aging day solution a) 0 day, b) 2 days, c) 7 days and d) 11 days 
The average crystallite sizes (D) of the YIG films were calculated by EVA software using the DebyeScherrer's formula. The average crystal size was calculated from the average of all peaks of garnet from the result. The sizes are in the range of 20 to $27 \mathrm{~nm}$. The crystallite size becomes bigger as the annealing temperature and aging time increase.

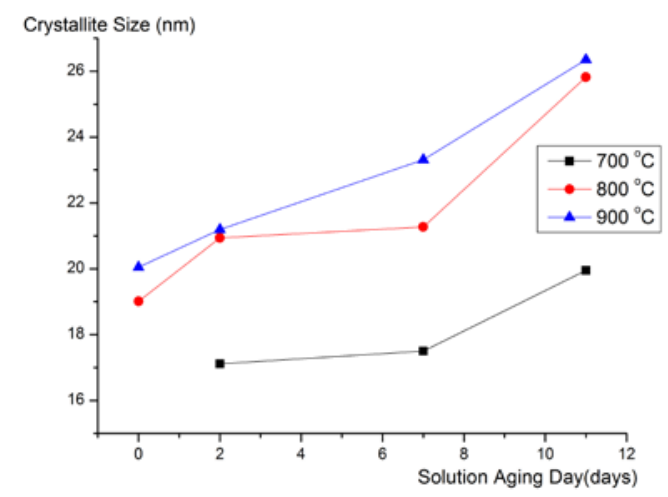

Figure 2. Crystallite size with different solution aging days

Table 1. Crystallite size, average particle size, thickness, Saturation Magnetization and coercivity YIG thin films

\begin{tabular}{cccc}
\hline $\begin{array}{c}\text { Annealing Temperature } \\
\left({ }^{\circ} \mathrm{C}\right)\end{array}$ & $\begin{array}{c}\text { Aging days of solution } \\
(\text { days })\end{array}$ & $\begin{array}{c}\text { Average Particle Size }( \pm 0.01) \\
(\mathrm{nm})\end{array}$ & $\begin{array}{c}\text { Thickness }( \pm 0.01) \\
(\mathrm{nm})\end{array}$ \\
\hline 700 & 0 & 19.68 & 58.08 \\
& 2 & 25.53 & 51.36 \\
& 7 & 34.30 & 64.76 \\
& 11 & 37.00 & 49.13 \\
& 0 & 29.92 & 57.22 \\
& 2 & 33.49 & 66.97 \\
& 7 & 42.63 & 69.22 \\
& 11 & 44.78 & 71.45 \\
& 0 & 33.27 & 55.26 \\
& 2 & 39.26 & 69.00 \\
& 7 & 49.12 & 72.63 \\
\end{tabular}

\subsection{Morphological of YIG Thin Films}

The morphology of the film surface was analyzed by a Field Emission Scanning Electron Microscope (FESEM) at the magnification of $50000 \mathrm{X}$. Figure 3 shows the typical surface image and a cross section for YIG films. Table 1 summarizes the films' grain size and thickness. The film's average grain size and thickness increase as YIG solution aging days increased for each annealing temperature. The average grain size is determined by measuring the 20 diameters of particle size, which look the same size using FESEM. For the increasing grain size, it is because the molecules in solution joint together forming larger molecules to form a gel with increasing aging time [16]. 


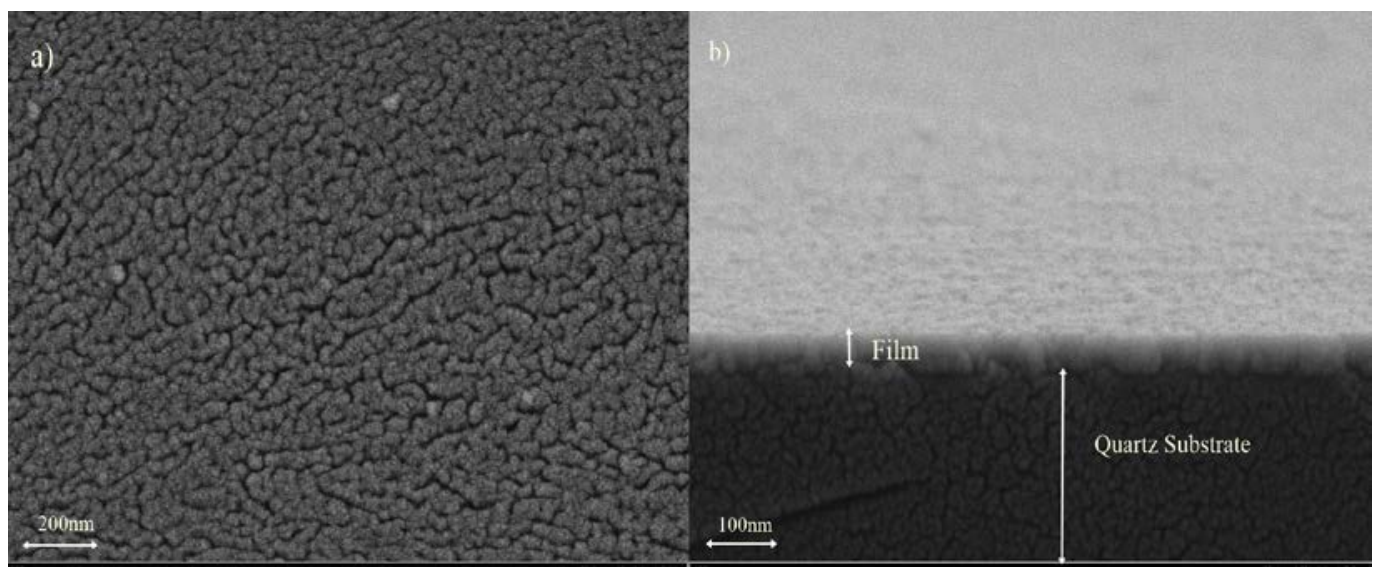

Figure 3. Typical FE-SEM image of YIG thin film a) surface b) cross-section

\subsection{Magnetic Properties}

Fig.4 shows the hysteresis loops for different aging YIG solution and annealing temperature measured by VSM at a room temperature of $27{ }^{\circ} \mathrm{C}$. In YIG, the yttrium ion in $24 \mathrm{c}$ (dodecahedral) sites does not have a magnetic moment and so the iron ion in 16a (octahedral) and 24d (tetrahedral) sites carry a magnetic moment due to superexchange interaction between $\mathrm{Fe}^{3+}$ and $\mathrm{Fe}^{2+}$ ions. Table 1 shows that the saturation magnetization value changes in a similar pattern as the changes of the average film particle size. The saturation magnetization increases with increasing particle size. Rajendra et al [11] also reported that the magnetic properties of YIG are dependent with particle size. The 9 and $14 \mathrm{~nm}$ particle have typical superparamagnetic behavior. Small particles have a higher surface to volume ratio (S/V) compared to larger particles, hence their surface spins effect is larger thus reducing the saturation magnetization value [4]. Fig 5 shows the saturation magnetization values increase with the increasing particle size, except for YIG film annealing at $700{ }^{\circ} \mathrm{C}$ with 7 days aging YIG solution.

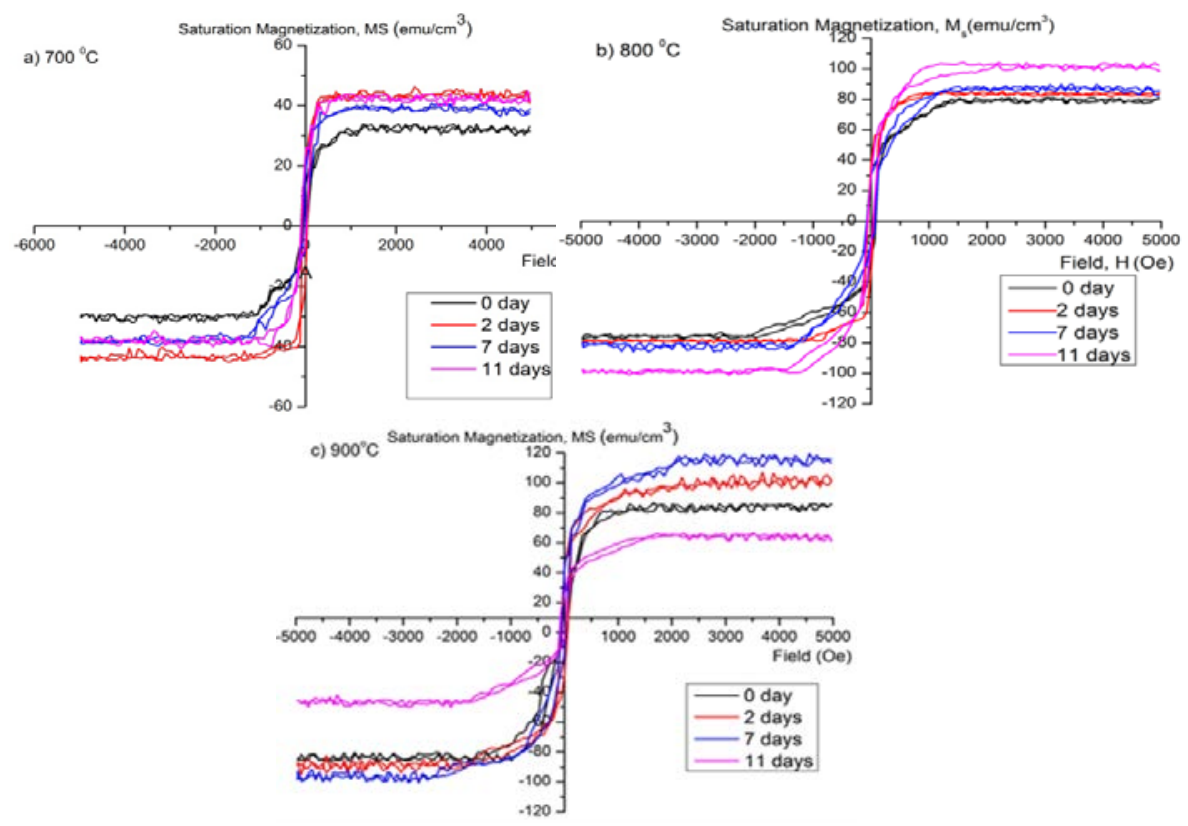

Figure 4. Hysteresis loop 0, 2, 7 and 11 days aging solution for each annealing temperature, a) $700^{\circ} \mathrm{C}$; b) $800^{\circ} \mathrm{C} ; \mathrm{c}$ ) $900^{\circ} \mathrm{C}$ 


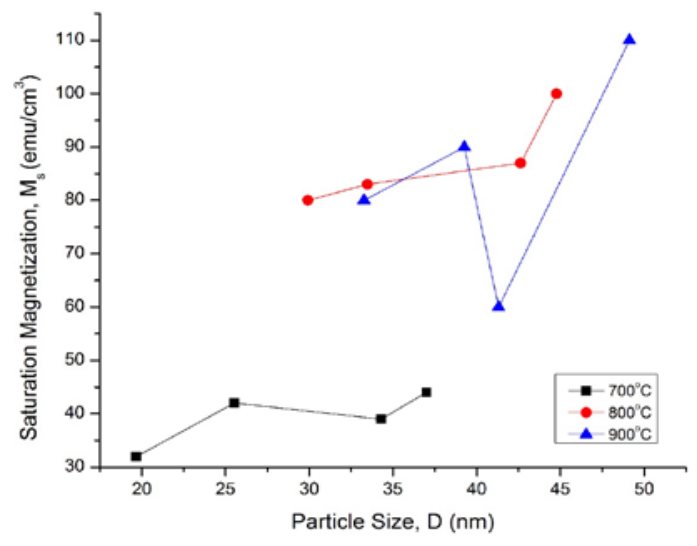

Figure 5. Saturation Magnetization versus Particle Size with different annealing temperature a) $700^{\circ} \mathrm{C}$; b) $800^{\circ} \mathrm{C}$; c) $900^{\circ} \mathrm{C}$

\section{Conclusion}

Yttrium iron garnet thin films with different annealing temperature and aging time have been successfully prepared by a sol-gel method. Aging time reduced the annealing temperature to crystallize YIG film. Higher annealing temperature and longer aging time produced thicker films with bigger particle size. The saturation magnetization increased with an increasing aging time solution.

\section{References}

1. P. Vaqueiro, M.A. López-Quintela, J. Rivas, J.M. Greneche, "Annealing dependence of magnetic properties in nanostructured particles of yttrium iron garnet prepared by citrate gel process," Journal of Magnetism and Magnetic Mateials, vol. 169, pp. 556-68, 1997.

2. P. Vaqueiro, M.P. Crosnier-Lopez, M.A. López-Quintela, "Synthesis and Characterization of Yttrium Iron Garnet Nanoparticles," Journal of Solid State Chemistry, vol. 126, pp. 161-168, 1996

3. Ftema W. Aldbea, N. I. Ahmad, N. B. Ibrahim , M. Yahya, (2014) "Effect of increasing pH value on the structural optical and magnetic properties of yttrium iron garnet films prepared by a sol-gel method," Journal Sol-Gel Science Technology, 2014.

4. R.D Sànchez, J. Rivas, P. Vaqueiro, M.A. López-Quintela, D. Caeiro, "Particle size effects on magnetic properties of yttrium iron garnets prepared by a sol-gel method", Journal of Magnetism and Magnetic Mateials, vol. 247, pp. 92-98, 2002.

5. Hongtao Yu, Liwen Zeng, Chao Lu, Wenbo Zhang, Guangliang Xu, "Synthesis of nanocrystalline yttrium iron garnet by low temperature solid state reaction," Materials Characterization, vol. 62, pp. 378-381, 2011.

6. A.C. Rastogi, V.N. Moorthy, "Magnetic properties of multilayers of nano thin Co,Ce-doped and undoped yttrium iron garnet films for magneto-optic applications," Materials Science and Engineering, vol. B95, pp. 131-136, 2002.

7. Botao Huang, Rui Ren, Zhao Zhang, Shuping Zheng, "The improvement of dispersibility og YIG precursor prepared via chemical coprecipitation," Journal of Alloys and Compounds, vol. 558, pp. 56-61, 2013.

8. N.B. Ibrahim, S.M. Al-Shomar, Sahrim Hj. Ahmad, "Effect of aging time on the optical, structural and photoluminescene properties of nanocrystalline ZnO films prepared by a so-gel method," Applied Surface Science, vol. 283, pp. 599-602, 2013.

9. Ebru Mensur Alkoy, Sedat Alkoy, Tadashi Shiosaki, "The effect of crystallographhic orientation and solution aging on the electrical propertis of sol-gel derived $\mathrm{Pb}\left(\mathrm{Zr}_{0.45} \mathrm{Ti}_{0.55}\right) \mathrm{O}_{3}$ thin films," Ceramics International, vol. 33, pp. 1455-1462, 2007.

10. S.M. Rozati, S. Moradi, S. Golshahi, R. Martins, E. Fortunato, "Electrical, structural and optical properties of flouorine-doped zinc oxide thin films: Effect of the solution aging time," Thin Solid Films, vol. 518, pp. 1279-1282, 2009. 
11. M. Rajendran, S. Deka, P.A. Joy, A.K. Bhattachary, (2006) "Size-dependent magneticproperties of nanocrystalline yttrium iron garnet powders" Journal of Magnetism and Magnetic Material, vol. 301, pp. 212-219, 2006. 